\title{
Modification of nanoscale thermal oxide films formed on indium phosphide under the influence of tin dioxide
}

\author{
I. Ya. Mittova, V. F. Kostryukov, N. A. Ilyasova, B. V. Sladkopevtsev, A. A. Samsonov \\ Voronezh State University, Universitetskaya pl., Voronezh, 394018, Russia \\ imittova@mail.ru,vc@chem.vsu.ru, ilyasova_1997@mail.ru,dp-kmins@yandex.ru, samsonjr@mail.ru
}

DOI 10.17586/2220-8054-2020-11-1-110-116

\begin{abstract}
The kinetic parameters and the limiting stage of the defining process were established by studying the thermal oxidation of $\mathrm{SnO}_{2} / \mathrm{InP}$ heterostructures (thickness of $\mathrm{SnO}_{2}$ layer $\sim 50 \mathrm{~nm}$ ). It was established that $\mathrm{SnO}_{2}$ does not have a chemical stimulating effect on the film growth rate; however, it is effective as a modifier of their structure and properties. $\mathrm{SnO}_{2}$ provides the formation of nanoscale films with semiconductor properties.
\end{abstract}

Keywords: indium phosphide, nanoscale films, thermal oxidation, tin dioxide.

Received: 8 November 2019

Revised: 16 January 2020

\section{Introduction}

The high transparency and conductivity of tin dioxide films allows them to be used as transparent conductive layers, and the sensitivity of their properties to surface conditions - as resistive sensors in gas sensors [1-3]. However, the application of $\mathrm{SnO}_{2}$ as a material for gas sensors is limited by low selectivity due to a large number of active centers on the surface that can interact with the molecules of many gases [4]. On the other hand, doping $\mathrm{SnO}_{2}$ with various elements, for example, antimony, allows one to increase the selectivity [5]. The chemical nature of the dopant and its acid-base and redox properties play key roles in determining the response to a detected gas. The selection of a suitable dopant modifier is based on an analysis of the chemical properties of detectable gases and the eventual interactions of the gas with a surface.

Pure stoichiometric $\mathrm{SnO}_{2}$ is an insulator, however pure but nonstoichiometric $\mathrm{SnO}_{2}$ is oxygen deficient and it is an n-type semiconductor with high conductivity at room temperature [6]. Although there are two stable tetragonal modification oxides, in the tin-oxygen system, $\mathrm{SnO}$ and $\mathrm{SnO}_{2}, \mathrm{SnO}$ does not find such widespread application due to its lower thermodynamic stability than $\mathrm{SnO}_{2}$ [7].

Due to its combination with InP components, the mixed indium-tin oxide (ITO structure) has several outstanding properties: almost metallic conductivity, good transparency in the visible range of electromagnetic radiation and the simplicity for formation of a nanoscale thin film. The optical and electrical properties are explained by the following: replacing the indium atom, tin supplies an additional electron to the conduction band, and such doping effectively increases the electron concentration [8].

ITO is widely used as transparent conductive coatings in the production of liquid crystal displays, laptop monitors, electroluminescent lamps, electrodes of photoconductive cells, fuel cells (including high-temperature ones), etc. [9, $10]$.

ITO are most often obtained by sputtering from ceramic targets, but since target regeneration is a rather complex and lengthy process, there are both traditional, reagent processing methods and methods based on cathode and anode processing [11].

It is known that by controlling the content of tin dioxide, it is possible to obtain ITO films with crystalline and amorphous structures and certain electrical and optical properties [12].

The deposition of metals such as Mo and Ni on the ITO structure can improve the mechanical properties and increase its corrosion resistance [13], while the deposition of copper-based conductive pastes on the ITO surface can increase the lifetime of electronic devices [14].

ITO structures are widely used as elements of recording devices. In particular, organic recording devices with an active layer located between two electrodes are becoming more popular. The use of ITO is determined by the low power consumption of these devices and simplicity of its production [15]. Today, there are recording devices, the basis of which is amorphous ITO, allowing extending the lifetime of such devices [16].

The thermodynamic calculation of the corresponding reactions using data [17] shows that $\mathrm{SnO}_{2}$ can theoretically transfer oxygen to the InP components, in other words it is a chemical stimulator of the semiconductor thermal oxidation [18]. Good reconcilability of oxide components, in particular, during the formation of ITO films, can serve as the basis for the modifying effect of tin dioxide [19] on the structure and electrophysical properties of thermal oxide films 
on InP. Accordingly, the purpose of this study was establishment of the effect of $\mathrm{SnO}_{2}$ as a possible chemostimulator and modifier of the structure and properties of nanoscale films grown by InP thermal oxidation.

\section{Experimental}

Nanoscale thin films grown on two-sided polished single-crystal (100)-oriented indium phosphide, doped with tin, the concentration of the main charge carriers at $300 \mathrm{~K}$ is more than $5 \cdot 10^{16} \mathrm{~cm}^{-3}$, intrinsic n-type conductivity, pretreated with an etchant of $\mathrm{H}_{2} \mathrm{SO}_{4}$ composition (chemical grade GOST-4204-77, 92.80\%): $\mathrm{H}_{2} \mathrm{O}_{2}$ (OSCh TU 602-570-750, $56 \%): \mathrm{H}_{2} \mathrm{O}=2: 1: 1$ for 10 min were studied. After repeated washing in distilled water and air-drying the plates, $\mathrm{SnO}_{2} / \mathrm{InP}$ heterostructures were formed in a Covap II vacuum ion sputter by the magnetron sputtering. The sputtering process was performed in a chamber with a pressure of $2 \cdot 10^{-5} \mathrm{~mm} \mathrm{Hg}$. The source material was $\mathrm{Sn}$ with a purity of $99.99 \%$, and the ion source was $\mathrm{O}_{2}+\mathrm{Ar}$ gases with a purity of $99.99 \%$. In order to obtain the $\mathrm{SnO}_{2}$ crystal structure on the InP surface, the semiconductor substrate was heated to $200^{\circ} \mathrm{C}$ during magnetron sputtering [20]. According to laser ellipsometry (LE), the thickness of the $\mathrm{SnO}_{2}$ layer on the InP surface was $50 \mathrm{~nm}$.

Thermal oxidation of $\mathrm{SnO}_{2} / \mathrm{InP}$ samples was carried out in an MTP-2M-50-500 resistance heating furnace. The volumetric oxygen flow rate was $30 \mathrm{~L} / \mathrm{h}$ (the corresponding linear speed is $10 \mathrm{~cm} / \mathrm{min}$ ) at $475,500,530$, and $550{ }^{\circ} \mathrm{C}$. The total thermal oxidation time was $60 \mathrm{~min}$. The sample was perpendicular to the oxygen flow. The temperature in the reactor was maintained constant $\left( \pm 1^{\circ} \mathrm{C}\right)$ by a TRM-10 PID controller. The thickness of the formed film was determined by laser ellipsometry (LEF-754, $\lambda=632.8 \mathrm{~nm}$, absolute error $\pm 1 \mathrm{~nm}$ ) and spectral ellipsometry (SE) (Ellipse-1891, operating in a range of wave lengths from 250 to $1100 \mathrm{~nm}$ ) every 10 minutes before the process time limit of 60 minutes was reached.

The need to use two methods for measuring the film thickness is due to the fact that only their combination allows obtaining the most accurate result [21-23], which is especially important when studying the considered nanoscale systems.

The composition of the films grown by thermal oxidation was determined by the XRD method on an ARL X'TRA $\mathrm{X}$-ray diffractometer. The X-ray diffraction patterns were recorded in the geometry of a sliding beam (with a fixed position of the arm of the X-ray tube). The several samples were studied by this method: $\mathrm{SnO}_{2} / \mathrm{InP}$ (oxidation at $475{ }^{\circ} \mathrm{C}$ ), $\mathrm{SnO}_{2} / \mathrm{InP}$ (oxidation at $500{ }^{\circ} \mathrm{C}$ ) and $\mathrm{SnO}_{2} / \mathrm{InP}$ (oxidation at $530{ }^{\circ} \mathrm{C}$ ). The starting angle for the samples oxidized at 475 and $5300^{\circ} \mathrm{C}$ was $-2 \theta=10^{\circ}$, the last $-2 \theta=70^{\circ}$ scan step $-0.05^{\circ}$. The starting angle for the samples oxidized at $500{ }^{\circ} \mathrm{C}$ was $-2 \theta=20^{\circ}$, the last $-2 \theta=80^{\circ}$ scan step $-0.06^{\circ}$.

The surface morphology of the samples was examined by scanning tunnelling microscopy (STM) using the complex of nanotechnological equipment UMKA in direct current mode and atomic force microscopy (AFM) on an SolverP47 Pro scanning probe microscope.

According to the value of resistivity, it is possible to draw the corresponding conclusions about the properties of the formed films: whether they have the ohmic conductivity, possess semiconductor or dielectric properties [24]. For this, aluminium contacts were magnetron sputtered on the surface of the synthesized samples in vacuum through a mask with holes with an area of $5 \cdot 10^{-3} \mathrm{~cm}^{2}$ and the resistivity $\rho(\mathrm{Ohm} \cdot \mathrm{cm})$ of the formed structures was determined using an Agilent 344 10A universal multimeter. In the process of measuring $\rho$, the thickness of the formed film was taken into account.

\section{Results and discussion}

Figure 1 shows kinetic curves (LE) for the thermal oxidation in double logarithmic coordinates of $\mathrm{SnO}_{2} / \mathrm{InP}$ heterostructures at $475-550{ }^{\circ} \mathrm{C}$ for 60 minutes.

The kinetic data were analysed using the power law equation:

$$
d=(k \cdot t)^{n},
$$

where $d(\mathrm{~nm})$ is the film thickness, $\tau(\min )$ is the oxidation time, $n$ is a formal kinetic parameter, and $k\left(\mathrm{~nm}^{1 / n} / \mathrm{min}\right)$ is the rate constant of the process [20].

The value of the effective activation energy (EAE) was determined from the Arrhenius dependence of the averaged process rate constant $\ln k_{c p}=f\left(10^{3} / R T\right)$. The exponent $n$, considered together with the EAE, gives information about the nature of the determining process and its limiting stage [26].

The calculated value of $n_{a v}, 0.05$, indicates that in the temperature range $475-550{ }^{\circ} \mathrm{C}$ the determining process is the mutual diffusion of the film components [18]. The value of the EAE is $48 \mathrm{~kJ} / \mathrm{mol}$, and even taking into account an error (of the order of $10 \%$ ), it cannot be equal to the EAE of the indium phosphide oxidation $(\sim 170 \mathrm{~kJ} / \mathrm{mol})$, for which the limiting stage of the process is a solid-phase reaction limited by diffusion of the substrate components (In) to the outer interface [24]. Such a low value of the EAE of the thermal oxidation process of $\mathrm{SnO}_{2} / \mathrm{InP}$ heterostructures, 


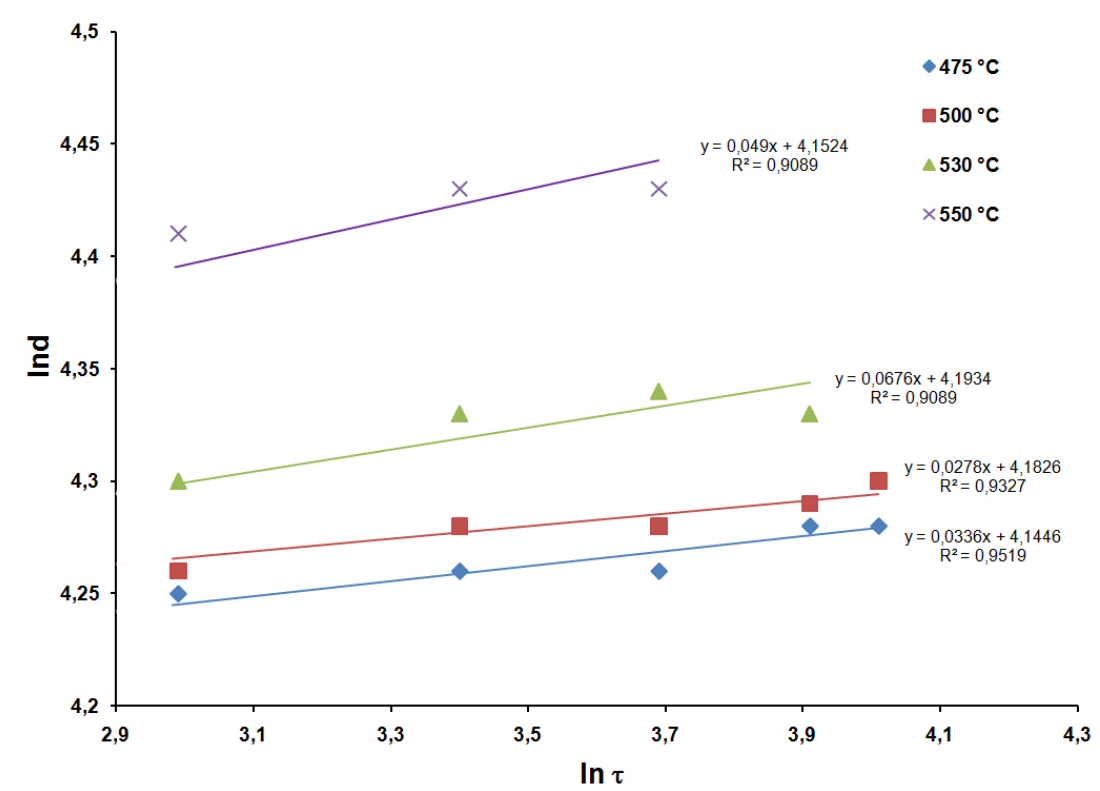

FIG. 1. Loglog plots of kinetic isotherms for the $\mathrm{SnO}_{2} / \mathrm{InP}$ heterostructures thermal oxidation process at $475-550{ }^{\circ} \mathrm{C}$ during 60 minutes

as well as a very small value of $n_{a v}$, just confirms the "diffusion mixing" as a limiting stage of the whole process (Table 1).

TABLE 1 . Kinetic parameters of the thermal oxidation process of the $\mathrm{SnO}_{2} / \mathrm{InP}$ heterostructures at $475-550^{\circ} \mathrm{C}$

\begin{tabular}{|c|c|c|c|}
\hline \multicolumn{2}{|c|}{ Kinetic parameters } & \multicolumn{1}{|c|}{$\boldsymbol{n} \pm \boldsymbol{\Delta}, \mathbf{n m}^{\mathbf{1} / \boldsymbol{n}} \mathbf{m i n}^{-\mathbf{1}}$} & EAE, kJ/mol \\
\cline { 1 - 2 } $\boldsymbol{T},{ }^{\circ} \mathbf{C}$ & $\ln \boldsymbol{k}_{\boldsymbol{c p} .}$ & $0.03 \pm 0.023$ & \\
\hline 475 & 91.39 & $0.03 \pm 0.021$ & \multirow{2}{*}{48} \\
\hline 500 & 92.23 & $0.05 \pm 0.013$ & \\
\hline 530 & 91.56 & $0.07 \pm 0.014$ & \\
\hline 550 & 92.47 & $0.045 \pm 0.018$ & \\
\hline $\boldsymbol{n}_{\boldsymbol{a v} \boldsymbol{v}}$ & &
\end{tabular}

In order to evaluate the chemical stimulating effect of the nanosized $\mathrm{SnO}_{2}$ layer on the InP thermal oxidation process, we calculated the values of the relative change in the film thickness $b$ compared to the reference using the formula (2)

$$
b=\frac{d_{\mathrm{SnO}_{2} / \mathrm{InP}}-d_{\mathrm{SnO}_{2} / \mathrm{InP}}^{*}}{\Delta d_{\mathrm{InP}}},
$$

where $\Delta d_{\mathrm{InP}}$ is the change in the thickness of the oxide film during oxidation of indium phosphide (reference standard), $d_{\mathrm{SnO}_{2} / \mathrm{InP}}$ is the value of the thickness of the oxide film during oxidation of $\mathrm{SnO}_{2}$ at a certain oxidation time, and $d_{\mathrm{SnO}_{2} / \mathrm{InP}}^{*}$ is the thickness of deposited layer (without oxidation) [25].

However, the film thickness values obtained by the LE method $(80 \mathrm{~nm})$, even taking into account the error, do not coincide with the SE data $(60 \mathrm{~nm})$. This may be due to the fact that the Cauchy model allows one to obtain only an approximate film thickness [26]. In this regard, the results obtained by laser ellipsometry can be considered more reliable. 
At all temperatures $\left(475-550{ }^{\circ} \mathrm{C}\right)($ see Table 2$)$, there is no acceleration of film growth over the entire time. Small values of the corresponding Gibbs free energies of reactions ( $\Delta G=-273--211 \mathrm{~kJ} / \mathrm{mol})$ of oxygen transfer from tin dioxide to the substrate components in combination with the data of Table 2, indicate a slowing effect of tin dioxide on the InP oxidation rate and the certain barrier function of the deposited layer, serving as an obstacle for the oxidation of the components of the substrate.

TABLE 2. The values of the relative change of the film thickness formed in the process of thermal oxidation of $\mathrm{SnO}_{2} / \mathrm{InP}$ heterostructures at $475-550{ }^{\circ} \mathrm{C}$, calculated by the formula (2)

\begin{tabular}{|c|c|c|c|c|c|c|}
\hline \multicolumn{7}{|c|}{ Relative change of film thickness, times } \\
\hline $\boldsymbol{T},{ }^{\circ} \mathbf{C} / \boldsymbol{\tau}, \mathbf{m i n}$. & 10 & 20 & 30 & 40 & 50 & 60 \\
\hline 475 & 0.18 & 0.26 & 0.32 & 0.3 & 0.32 & 0.32 \\
\hline 500 & 0.94 & 0.76 & 0.68 & 0.61 & 0.58 & 0.59 \\
\hline 530 & 0.14 & 0.21 & 0.26 & 0.25 & 0.22 & 0.38 \\
\hline 550 & 0.48 & 0.55 & 0.53 & 0.48 & 0.54 & 0.71 \\
\hline
\end{tabular}

We can now make a conclusion that $\mathrm{SnO}_{2}$ is not a chemical stimulator of the InP thermal oxidation process.

According to the results of X-ray phase analysis (Fig. 2), we can conclude that the thermal oxidation of $\mathrm{SnO}_{2} / \mathrm{InP}$ heterostructures at $475-530{ }^{\circ} \mathrm{C}$, metal tin does not form, as in the process of a transit interaction.

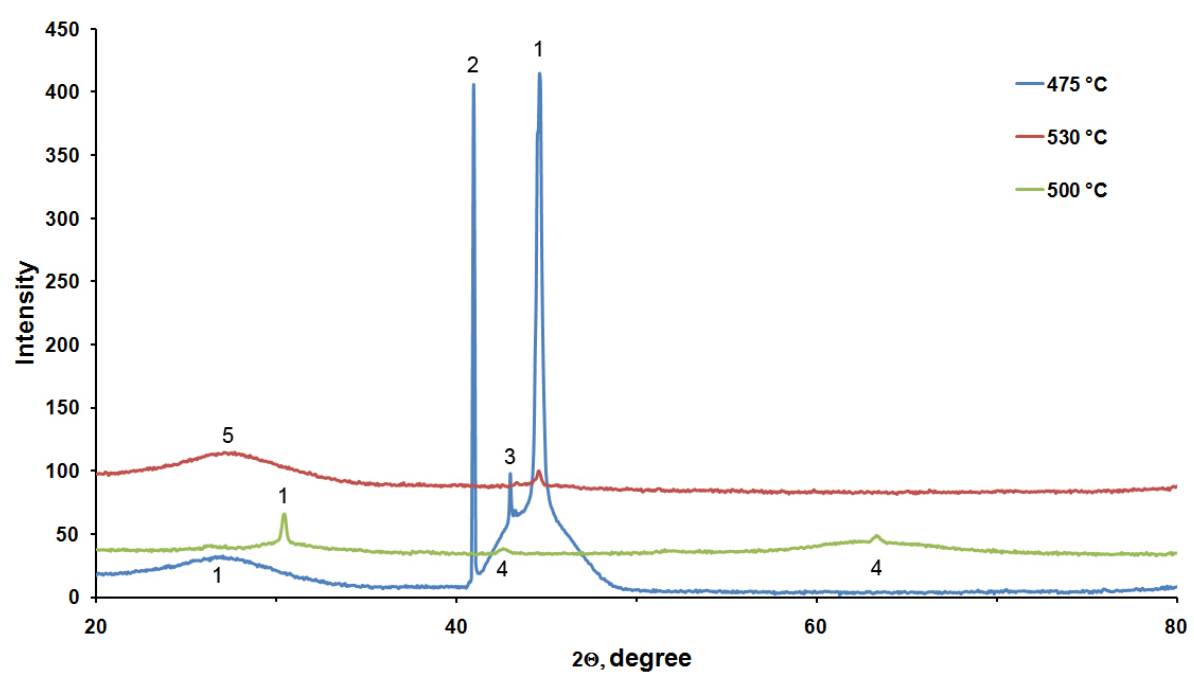

FIG. 2. X-ray diffraction patterns of the $\mathrm{SnO}_{2} / \mathrm{InP}$ heterostructures after thermal oxidation for 60 minutes at $475-530{ }^{\circ} \mathrm{C}$, where $1-\mathrm{In}\left(\mathrm{PO}_{3}\right)_{3}, 2-\mathrm{P}_{2} \mathrm{O}_{5}, 3-\mathrm{In}_{2} \mathrm{O}_{3}, 4-\mathrm{SnO}_{2}, 5-\mathrm{Sn}_{3}\left(\mathrm{PO}_{4}\right)_{2}$

Based on the presented diffractograms, we can conclude that the thermal oxidation of $\mathrm{SnO}_{2} / \mathrm{InP}$ heterostructures requires a relatively high temperature, from which $\mathrm{SnO}_{2}$ will interact with the substrate components. The presence of peaks corresponding to the compound $\mathrm{Sn}_{3}\left(\mathrm{PO}_{4}\right)_{2}$ indicates the interaction of the $\mathrm{SnO}_{2}$ layer deposited on the surface with the oxidation products of the substrate components, in particular phosphorus, and, therefore, a change in the composition of the film and its surface. Thus, we can speak about the modifying properties of $\mathrm{SnO}_{2}$. In this case, it is necessary to take into account the fact that the modification of nanoscale films with a thickness not exceeding $100 \mathrm{~nm}$ can ultimately lead to a noticeable change in the surface topography. For a number of practical applications, this is unacceptable, therefore, the study of the surface morphology of nanoscale films formed by the thermal oxidation of $\mathrm{SnO}_{2} / \mathrm{InP}$ heterostructures is a necessary task.

Films, formed during thermal oxidation of $\mathrm{SnO}_{2} / \mathrm{InP}$ heterostructures, have a fairly smooth surface (Figs. 3 and 4) at all oxidation temperatures, which is confirmed by AFM and STM methods. A feature of the InP surface is 
the presence of vacancy defects and a residual oxide phase, which leads to the formation of active centers. The growth of an oxide film during the oxidation of indium phosphide without chemical stimulators begins at these active centers [29].

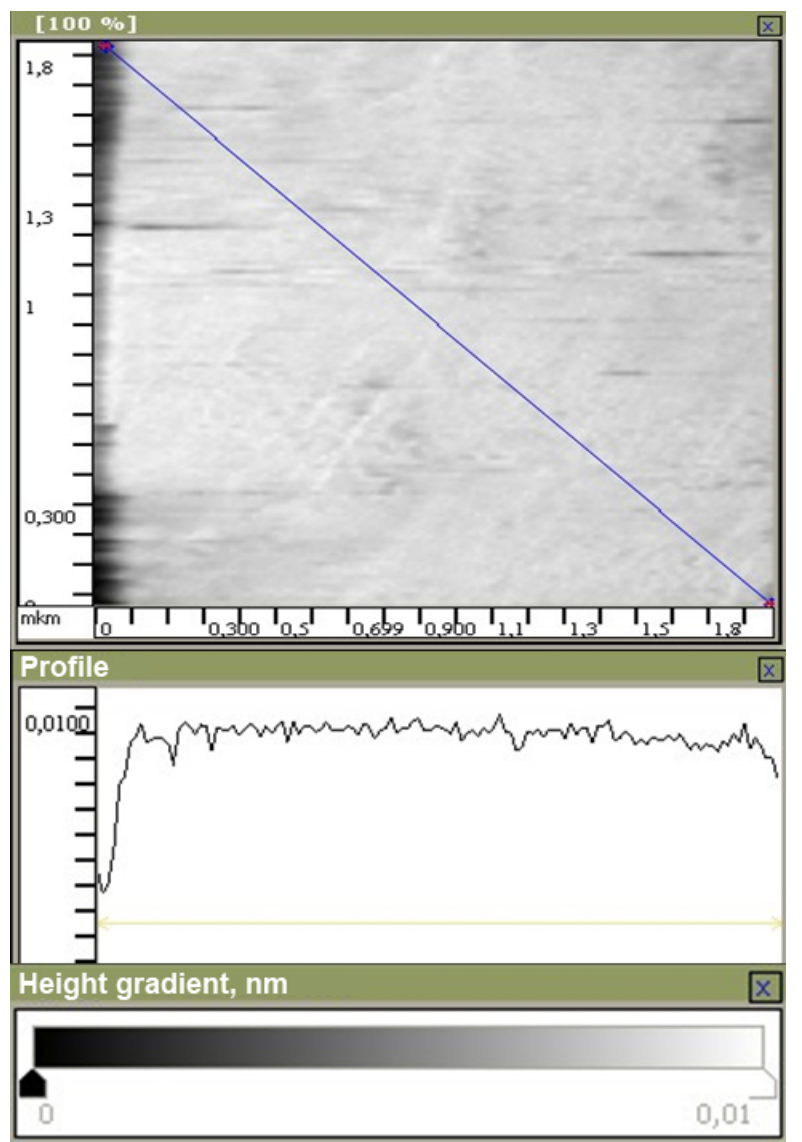

(a)

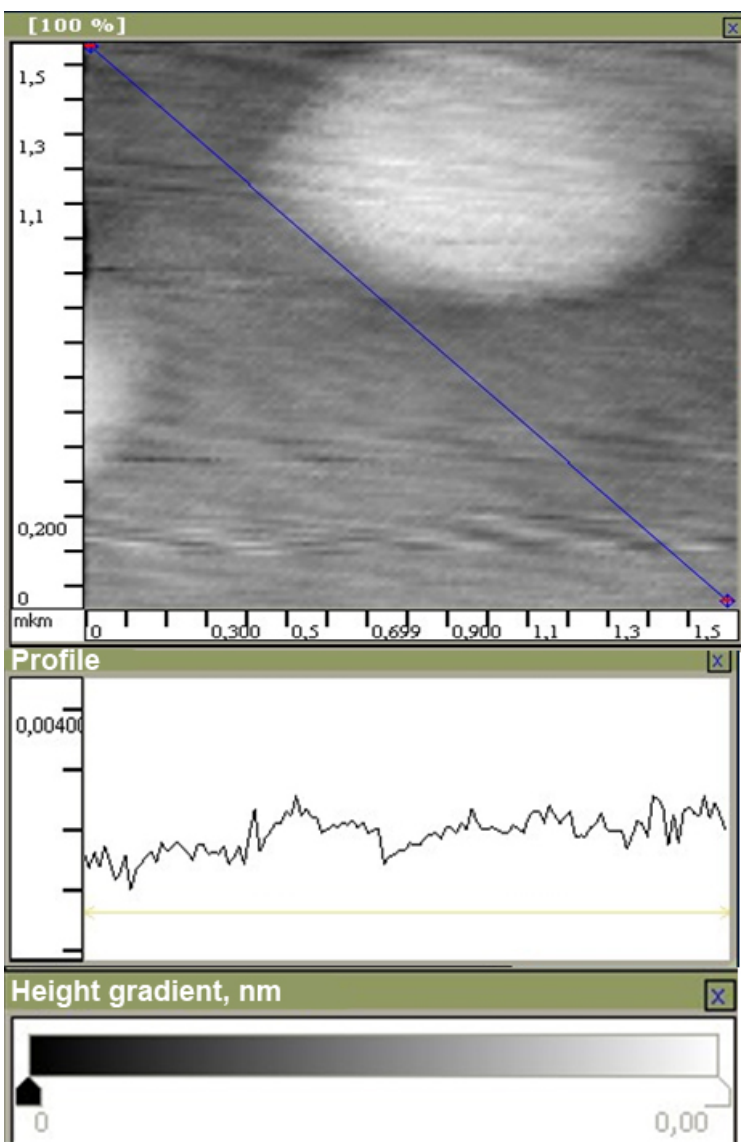

(b)

FIG. 3. STM images of $\mathrm{SnO}_{2} / \mathrm{InP}$ samples and their surface profile after oxidation at 500 (a) and at $550{ }^{\circ} \mathrm{C}$ (b) for 60 minutes. The scanning area was $1.8 \times 1.8$ and $1.5 \times 1.5 \mu \mathrm{m}^{2}$, respectively

According to the AFM data, the average roughness of the film is $S_{a}=1.065 \mathrm{~nm}$, that also confirms the smoothness of the films formed during the thermal oxidation process.

The resistivity of pure film $\mathrm{SnO}_{2}$ is $3.4 \cdot 10^{3} \mathrm{Ohm} \cdot \mathrm{cm} \mathrm{[30].} \mathrm{The} \mathrm{investigations} \mathrm{of} \mathrm{the} \mathrm{electrophysical} \mathrm{characteristics}$ showed that films synthesized as a result of thermal oxidation of $\mathrm{SnO}_{2} / \mathrm{InP}$ heterostructures have a higher electrical resistivity $\left(\rho=9 \cdot 10^{6} \mathrm{Ohm} \cdot \mathrm{cm}\right)$, indicating an improvement electrophysical properties. The semiconductor properties can be explained by the fact that no metal indium is released during the oxidation of $\mathrm{SnO}_{2} / \mathrm{InP}_{\text {heterostructures; }} \mathrm{SnO} \mathrm{O}_{2}$ promotes its chemical binding to phosphorus, as a result the formation of the corresponding phosphates occur. As a result, the suppression of ohmic conductivity was observed.

\section{Conclusion}

Thus, it was found that $\mathrm{SnO}_{2}$ is not a chemical stimulator of the InP thermal oxidation process. This was confirmed by the LE method that correlate with the data of thermodynamic calculations of the corresponding reactions. At the same time, $\mathrm{SnO}_{2}$ has a modifying effect on the composition and properties of nanoscale (thickness not more than $80-90 \mathrm{~nm}$ ) films synthesized by thermal oxidation, as evidenced by the presence of $\mathrm{Sn}_{3}\left(\mathrm{PO}_{4}\right)_{2}(\mathrm{XRD})$ phases in the films. When InP is thermally oxidized, conductive films, enriched with metallic indium and characterized by a very developed surface relief are formed. At the same time, during the oxidation of $\mathrm{SnO}_{2} / \mathrm{InP}$ heterostructures, semiconductor films are formed (the specific electrical resistance is $9 \cdot 10^{6} \mathrm{Ohm} \cdot \mathrm{cm}$ ), the average roughness of which is $1.065 \mathrm{~nm}$. 


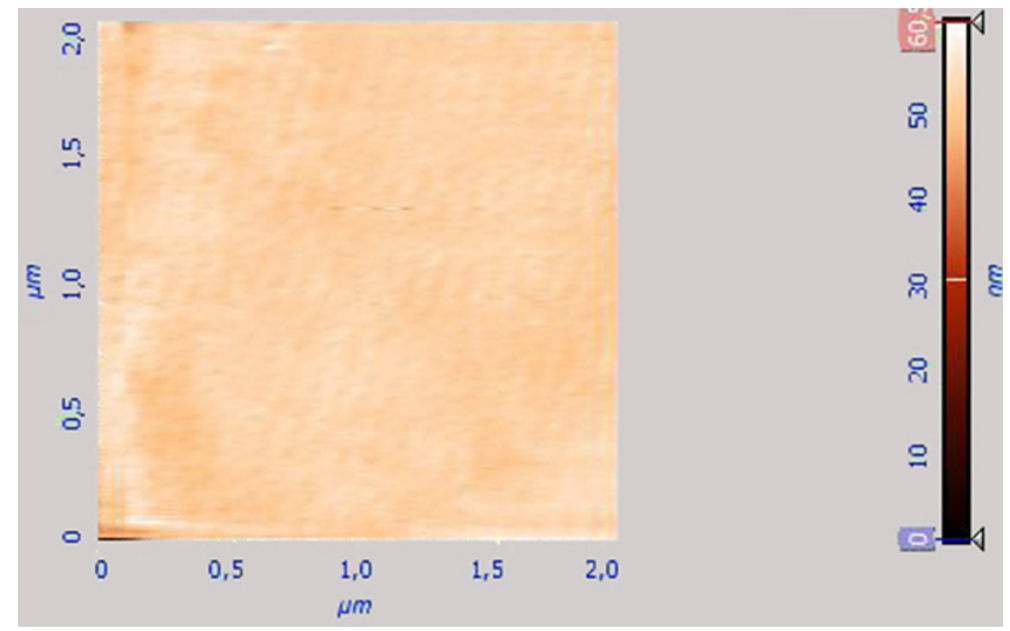

FIG. 4. FM image of the $\mathrm{SnO}_{2} / \mathrm{InP}$ heterostructure after thermal oxidation for $60 \mathrm{~min}$ at $530{ }^{\circ} \mathrm{C}$. The scan area was $2 \times 2 \mu \mathrm{m}^{2}$

\section{Acknowledgements}

This research was supported by the Russian Foundation for Basic Research, grant No. 18-03-00354a. The research results were partially obtained on the equipment of the Collective Use Centre of Voronezh State University. URL: http://ckp.vsu.ru.

\section{References}

[1] Shikova T.G., Kholodkov I.V., Talanov E.N. An investigation of the properties of tin oxide films produced by thermal oxidation of the metal films. Physics and chemistry of materials processing, 2011, 3 (6), P. 88-92.

[2] Krivetskiy V.V., Rumyantseva M.N., et al. Materials based on Modified $\mathrm{SnO}_{2}$ for Selective Gas Sensors. Inorganic Materials, 2010 , 46 (10), P. $1218-1224$

[3] Povarov V.G., Lopatnikov A.I. A simple multisensor detector based on tin dioxide in capillary gas chromatography. Journal of Analytical Chemistry, 2016, 71 (9), P. 940-945.

[4] Rumyantseva M.N, Makeeva E.A., Gaskov A.M. The effect on the chemisorption of oxygen on their surface the microstructure of semiconductor sensors materials. Russian Journal of General Chemistry, 2008, 52 (2), P. 122-129.

[5] Zhukova A.A., Rumyantseva M.N., et al. Influence of antimony doping on structure and conductivity of tin oxide whiskers. Thin Solid Films, 2009, 518, P. 1359-1362.

[6] Nasheksky A.Ya. AIIIBV semiconductor phosphides and solid solutions based on it. Mir, Moscow, 1974,154 p.

[7] Turishchev S.Yu., Yurakov Yu.A., et al. Synchrotron Investigations of Oxides Formation in Tin Nanolayers. Journal of Surface Investigation: X-Ray, Synchrotron and Neutron Techniques, 2007, 1, P. 66-70.

[8] Drozdov K.A., Krylov I.V., et al. Effect of the tin impurity on the energy spectrum photoelectric properties of nanostructured $\mathrm{In}_{2} \mathrm{O}_{3}$ films. Semiconductors, 2014, 48 (4), P. 467-470.

[9] Amosova L.P. Electrooptical properties and structural features of amorphous ITO. Semiconductors, 2015,49 (3), P. $414-418$.

[10] Yoon-Heung Tak, Ki-Beom Kim, et al. Criteria for ITO (indium-tin-oxide) thin film as the bottom electrode of an organic light emitting diode. Thin Solid Films, 2002, 411, P. 12-16.

[11] Belobaba A.G., Zelinsky A.G., Gusev A.A., Masliy A.I. Electrochemical Stability of Indium-Tin Oxides. Chemistry for Sustainable Development, 2014, 22 (4), P. 417-422.

[12] Rembeza S.I., Rembeza E.S., Voronov P.E., Sinelnikov B.M. Synthesis, structure and electrical properties of $\left(\mathrm{SnO}_{2}\right)_{x}\left(\mathrm{In}_{2} \mathrm{O}_{3}\right)_{1-x}(x=0.5-$ 1) nanocomposites. Semiconductors, 2011, 45 (11), P. 1538-1541.

[13] Ramasundari P., Ganeshan S., Vijayalakshmi R. Characterization studies on the novel mixed thin films. Nanosystems: Physics, Chemistry, Mathematics, 2016, 7 (4), P. 683-686.

[14] Begletsova N.N., Al-Alwani A.J.K., et al. Influence of copper nanoparticle film processing temperature on their structure and electrical properties. Nanosystems: Physics, Chemistry, Mathematics, 2018, 9 (5), P. 586-596.

[15] Gayathri A.G., Joseph C.M. Bistable electrical switching and performance of a pentacene-based write once/read many memory device. Nanosystems: Physics, Chemistry, Mathematics, 2016, 7 (4), P. 643-646.

[16] Wang Yaqin, Tang Wu. Surface-dependent conductivity, transition type, and energy band structure in amorphous indium tin oxide films. Solid State Electronics, 2017, 138, 10.1016/j.sse.2017.09.007.

[17] Glushko V.P. Thermodynamic properties of individual substances. 4. Nauka, Moscow, 1978, $386 \mathrm{p}$.

[18] Mittova I.Ya. Influence of the Physicochemical Nature of Chemical Stimulators and the Way They are Introduced into a System on the Mechanism of the Thermal Oxidation of GaAs and InP. Inorganic Materials, 2014, 50 (9), P. 948-955.

[19] Mittova I.Ya, Sladkopevtsev B.V., et al. Growth and Properties of Nanofilms Produced by the Thermal Oxidation of $\mathrm{MnO}_{2} / \mathrm{InP}_{\mathrm{P}}$ under the Effect of $\mathrm{Mn}_{3}\left(\mathrm{PO}_{4}\right)_{2}$. Inorganic Materials, 2019, 55 (9), P. 969-974. 
[20] Kim T.W., Lee D.U., Lee J.H., Yoon Y.S. Surface and microstructural properties of $\mathrm{SnO}_{2}$ thin films grown on p-InP (100) substrates at low temperature. Solid State Communications, 2000, 115, P. 503-507.

[21] Shvets V.A., Spesivtsev E.V., Rykhlitskii S.V., Mikhailov N.N. Ellipsometry as a high-precision technique for subnanometer-resolved monitoring of thin-films structures. Nanotechnologies in Russia, 2009, 4 (3-4), P. 91-102.

[22] Aspnes D.E. Optical properties of thin films. Thin solid films, 1982, 89, P. 249-262.

[23] Tomina E.V., Mittova I.Ya., Zelenina L.S. Thermal Oxidation as a Method of formation of Nanoscale Functional Films on A ${ }^{\text {III }} \mathrm{B}^{\mathrm{V}}$ Semiconductors: Influence of Deposited Metal Layers. Overview. Condensed Matter and Interphases, 2018, 20 (1), P. 6-24.

[24] Mittova I.Ya., Tomina E.V., et al. High-speed determination of the thickness and spectral ellipsometry investigation of films produced by the thermal oxidation of InP and VxOy/InP structures. Inorganic Materials, 2013, 49 (2), P. 173-179.

[25] Mittova I.Ya., Sladkopevtsev B.V., et al. Formation of nanoscale films of the $\left(\mathrm{Y}_{2} \mathrm{O}_{3}-\mathrm{Fe}_{2} \mathrm{O}_{3}\right)$ on the monocrystal InP. Condensed Matter and Interphases, 2019, 21 (3), P. 406-418.

[26] Synowicki R.A. Spectroscopic ellipsometry characterization of indium tin oxide film microstructure and optical constants. Thin Solid Films, 1998, 46 (20), P. 394-397.

[27] Mittova I.Ya., Borzakova G.V., et al. Growth of Oxide Layers on Indium Phosphide. Inorganic Materials, 2012,48 (2), P. $161-168$.

[28] Thilakan P., Kumar J. Reactive thermal oxidation of indium oxide and tin-doped indium oxide thin films on InP substrates. Thin Solid Films, 1997, 292, P. 50-54.

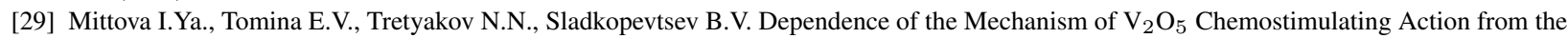
Method of its Introduction into the System during InP Thermal Oxidation. Condensed Matter and Interphases, 2013 , 15 (3), P. $305-311$.

[30] Kovtunenko P.V., Nesterova I.L., Knunyants I.L. Chemical Encyclopedia. Great Russian Encyclopedia, Moscow, 1992, 639 p. 